Perfor mance of repul si ve type magnetic bearing syst em under nonuni for $m$ magnet i zat $i$ on of per manent magnet

\begin{tabular}{|l|l|}
\hline 著者 & $\begin{array}{l}\text { Ohj i T., Mikhopadhyay S. C. , I wahar a } \\
\text { Nasay oshi, Yamada Sot oshi }\end{array}$ \\
\hline $\begin{array}{l}\text { j our nal or } \\
\text { publ i cat i on ti t l e }\end{array}$ & I EEE Tr ansact i ons on Nagnet i cs \\
\hline vol une & 36 \\
\hline number & 5 I \\
\hline page $\mathrm{r}$ ange & $3696-3698$ \\
\hline year & $2000-09-01$ \\
\hline URL & ht t p: //hdl . handl e. net /2297/6903 \\
\hline
\end{tabular}




\title{
Performance of Repulsive Type Magnetic Bearing System Under Nonuniform Magnetization of Permanent Magnet
}

\author{
T. Ohji, S. C. Mukhopadhyay, Member, IEEE, M. Iwahara, Member, IEEE, and S. Yamada, Member, IEEE
}

\begin{abstract}
Permanent magnet bearing system utilizes the repulsive forces between the stator and rotor permanent magnets (PM) for the levitation of the system and it results a simplified axial control scheme. A repulsive type magnetic bearing system based on the above principle was fabricated in our laboratory. Material characteristics and the configuration of the permanent magnets are the central component for this type of bearing system. Due to aging or as both the magnets are repelling each other, there will be demagnetization of the permanent magnet, resulting the field distribution along the magnet's periphery nonuniform. In this paper the effect of this magnetization nonuniformity on the performance of the bearing system has been studied.
\end{abstract}

Index Terms-Magnetic bearing, magnetization and nonuniformity, permanent magnet, repulsive type.

\section{INTRODUCTION}

$\mathbf{F}$ OR QUITE a long time, the authors are involved on the design and development of repulsive type magnetic bearing to be used for horizontal and vertical-shaft machines. Two types of models have been fabricated and developed in our laboratory and their performance are studied [1]-[3]. In repulsive type magnetic bearing system the permanent magnets are used for the levitation of the rotor and the system is stable along the radial direction. The forces acting between the stator and rotor permanent magnets along the radial direction are same, as a result the rotor is positioned in the center of the stator. This is based on the assumption that the magnetization of the stator and rotor permanent magnet is uniform.

The repulsive forces are developed as both the magnets are repelling each other, and as a result, there are possibility of demagnetization of the permanent magnet. Even with aging there will be a slight demagnetization. There may be some magnetization asymmetry due to some manufacturing defects or fabrication difficulties. Whatever may be the reason, this nonuniformity of magnetization has some effect on the performance of the bearing system. There will be oscillations of the rotor and in the worst case, the rotor may hit the stator inner surface. In this paper the authors intend to study this effect.

\section{SYSTEM CONFIGURATION}

Fig. 1 shows the configuration of the vertical-shaft magnetic bearing system fabricated in our laboratory. The stator and rotor

Manuscript received February 1, 2000.

The authors are with Kanazawa University, Kanazawa 920-8667, Japan (e-mail: chandra@magstar.ec.t.kanazawa-u.ac.jp).

Publisher Item Identifier S 0018-9464(00)07971-1.

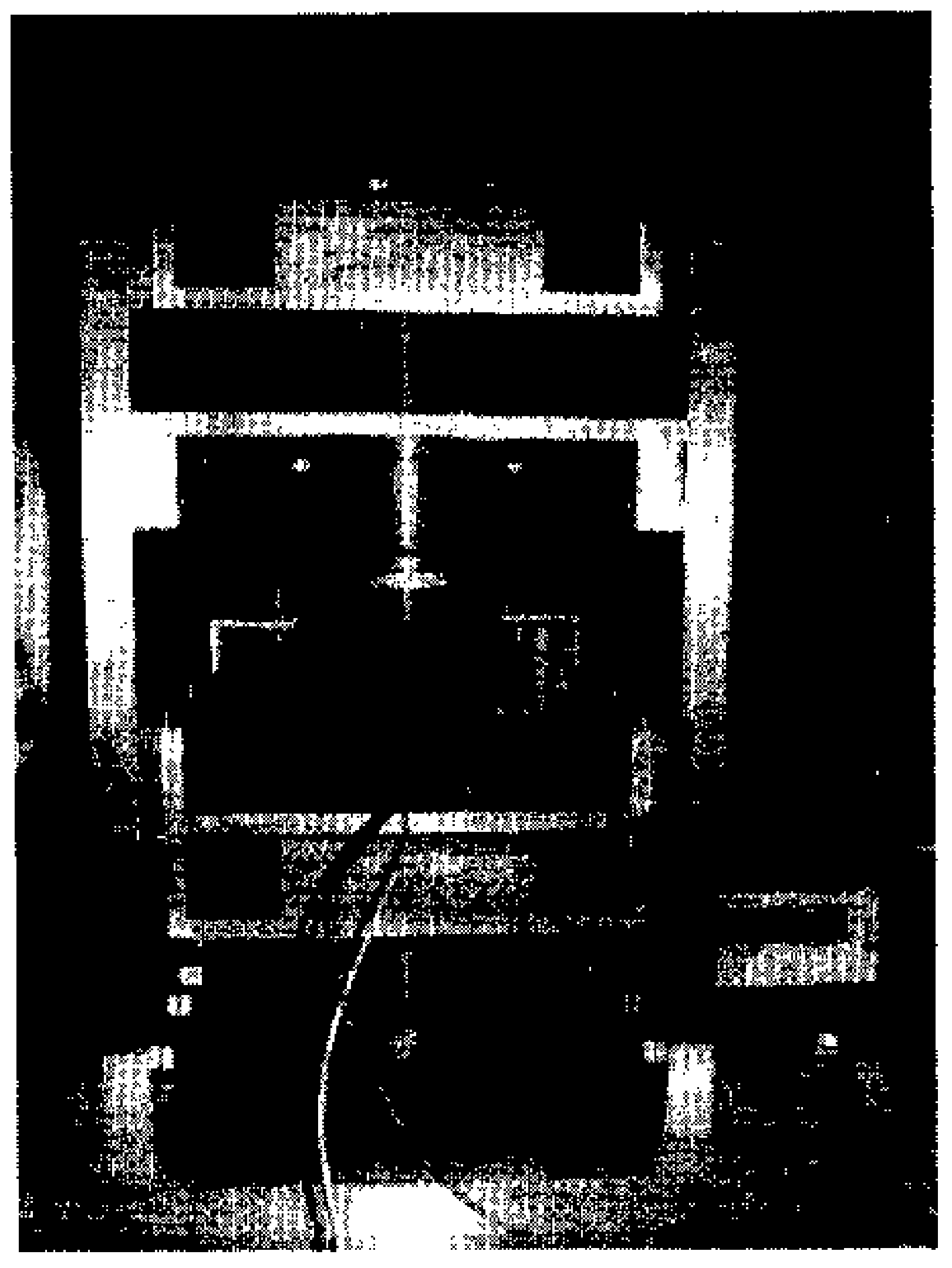

Fig. 1. Fabricated model of the magnetic bearing system.

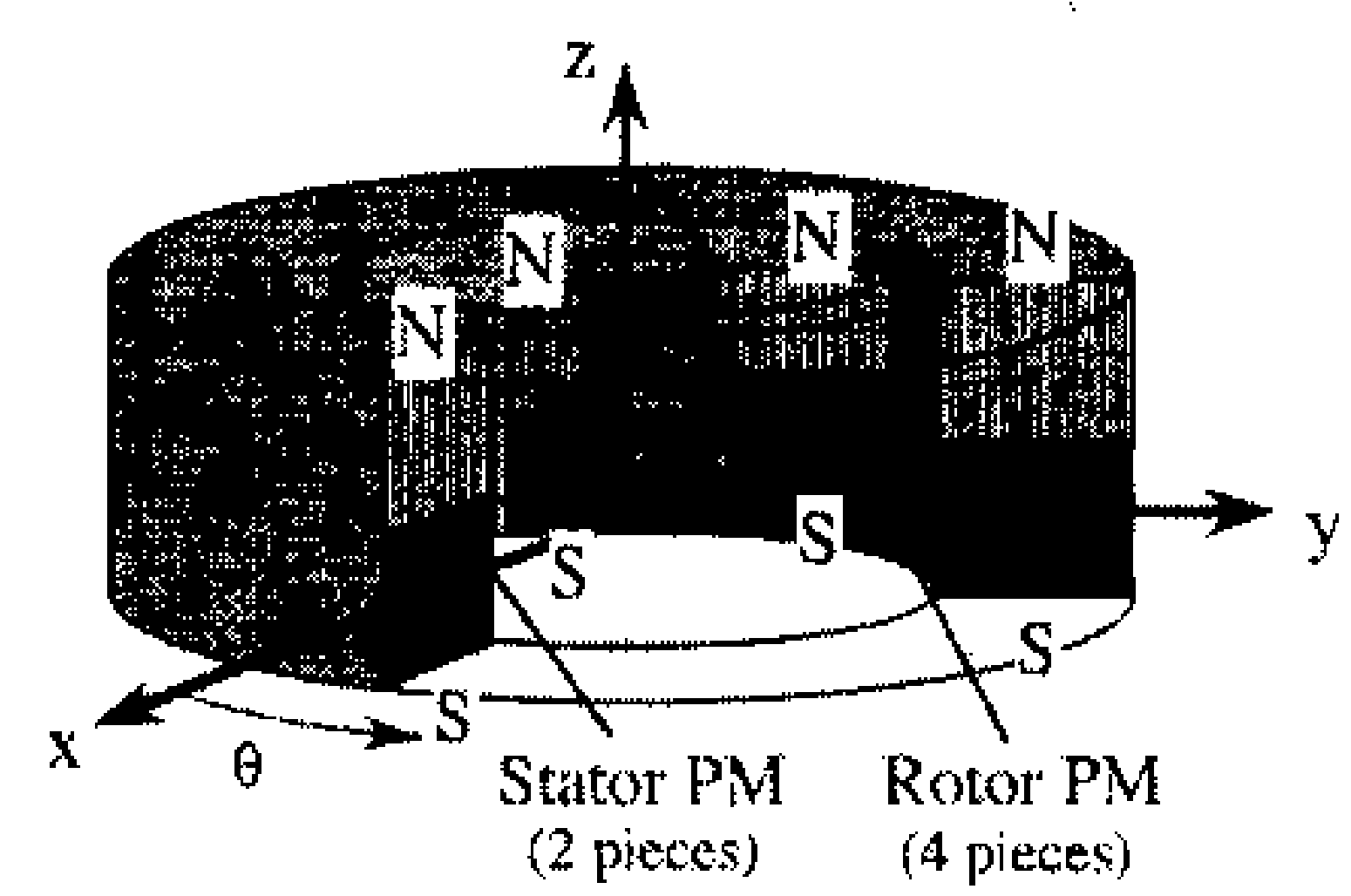

Fig. 2. Permanent magnet configuration.

PM's are placed at either end of the shaft. The stationary electromagnet, a rotor flywheel with conducting surface at one side and the induction motor are located at the middle of the shaft. The repulsive forces developed by the two sets of bearings are not sufficient to levitate the rotor [3]. So the current applied to the electromagnet is used to levitate the rotor as well as to control the axial position of the rotor. Gap sensor is used to measure the gap between the electromagnet surface and the flywheel surface. The mass of the rotor is $5.5 \mathrm{~kg}$, the length of the shaft is $420 \mathrm{~mm}$ and the diameter of the flywheel is $200 \mathrm{~mm}$.

Axially magnetized circular permanent magnet made of strontium-ferrite magnet has been used for the bearing. The configuration of the permanent magnet is shown in Fig. 2. Two magnets, each having outer diameter, inner diameter and 


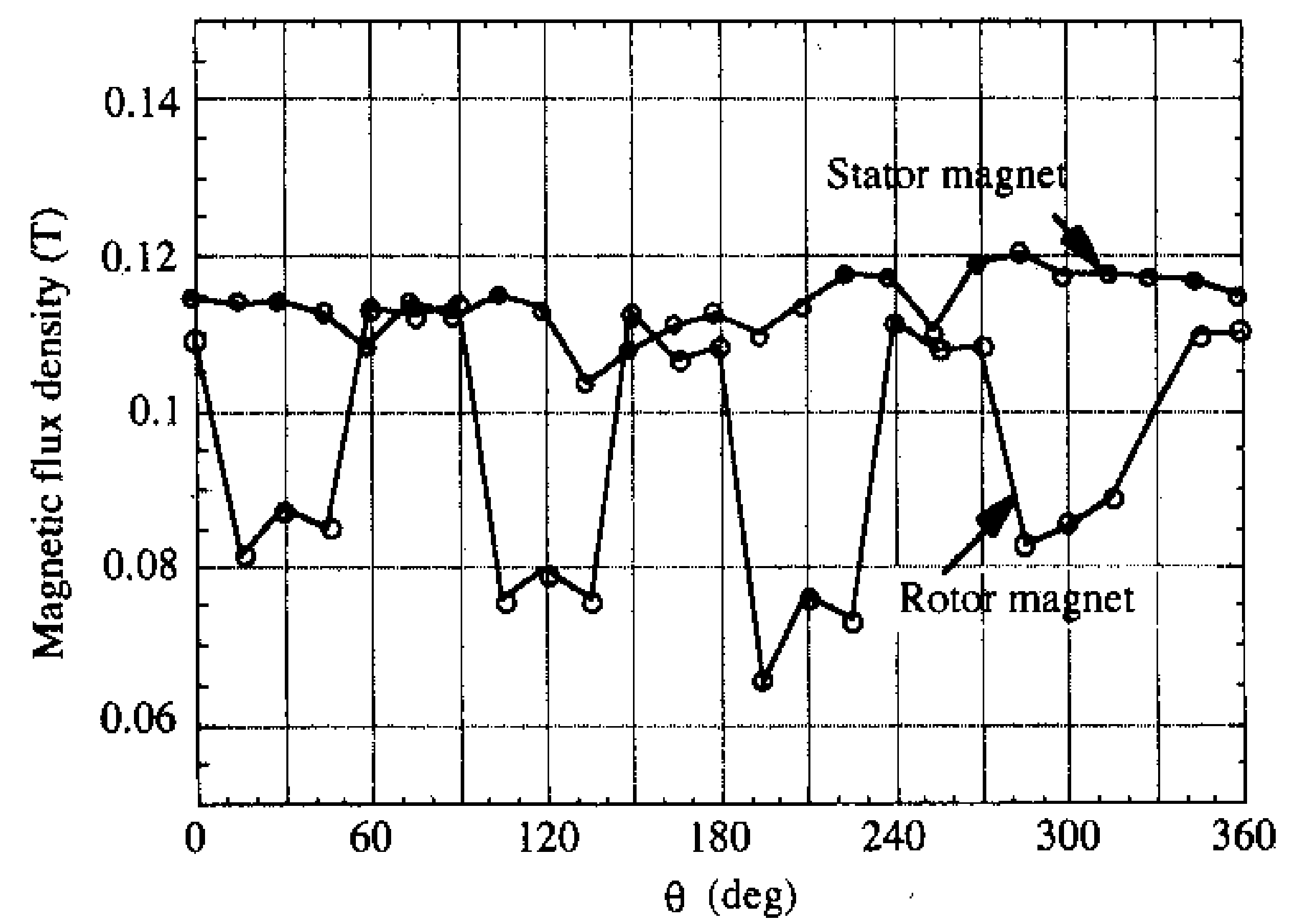

Fig. 3. Flux density distribution.

width of $100 \mathrm{~mm}, 60 \mathrm{~mm}$ and $15 \mathrm{~mm}$ respectively are used for the stator. Four magnets, each having outer diameter, inner diameter and width of $52.5 \mathrm{~mm}, 20 \mathrm{~mm}$ and $5 \mathrm{~mm}$ respectively are used for the rotor. The system is a single axis controlled system. $Z$-axis is the controlled axis and the $X, Y$ axes are the uncontrolled axes.

\section{VIBRATION CHARACTERISTICS}

The system was fabricated more than three years ago. At that time the field distribution around the periphery of each and every magnet was measured and found uniform. The performance of the system was also very much satisfactory. Recently the rotor shows unwanted oscillating vibration along the $X$ and $Y$ axes. Since those are the uncontrolled axes, the level of vibration has a limit on the stable operation of the bearing system.

In order to investigate the reasons of the vibration of the rotor, the flux-density distribution around the periphery of the magnets is measured again with the help of gauss meter. Fig. 3 shows the flux-density distribution along the periphery of the surface of the stator and the rotor magnet. It is seen that the field distribution is nonuniform in nature and is the main cause of the rotor vibration. This nonuniform field distribution has the effect of developing the unbalanced magnetic pull between the stator and the rotor permanent magnet which causes the unwanted vibration of the rotor. It has also the effect of generation of the eddy current in the rotor permanent magnet and consequently an increase in the power loss of the system.

The vibration characteristics with the nonuniform field distribution of the magnet has been measured. Fig. 4 shows the characteristics while only the rotor magnet has the nonuniformity and Fig. 5 shows the characteristics while only the stator magnet has the nonuniformity of the magnetization. It is seen that the stator nonuniformity has much more strong influence compared to the rotor nonuniformity and it has displaced the rotor from the central position. The effect of this nonuniformity on the energy storage has also been examined. Fig. 6 shows the deceleration characteristics of the rotor with the uniform and nonuniform magnetization of the PM's while the whole system is placed in a helium gas chamber. There is a slight effect on the rate of deceleration of the speed and in our experiment the

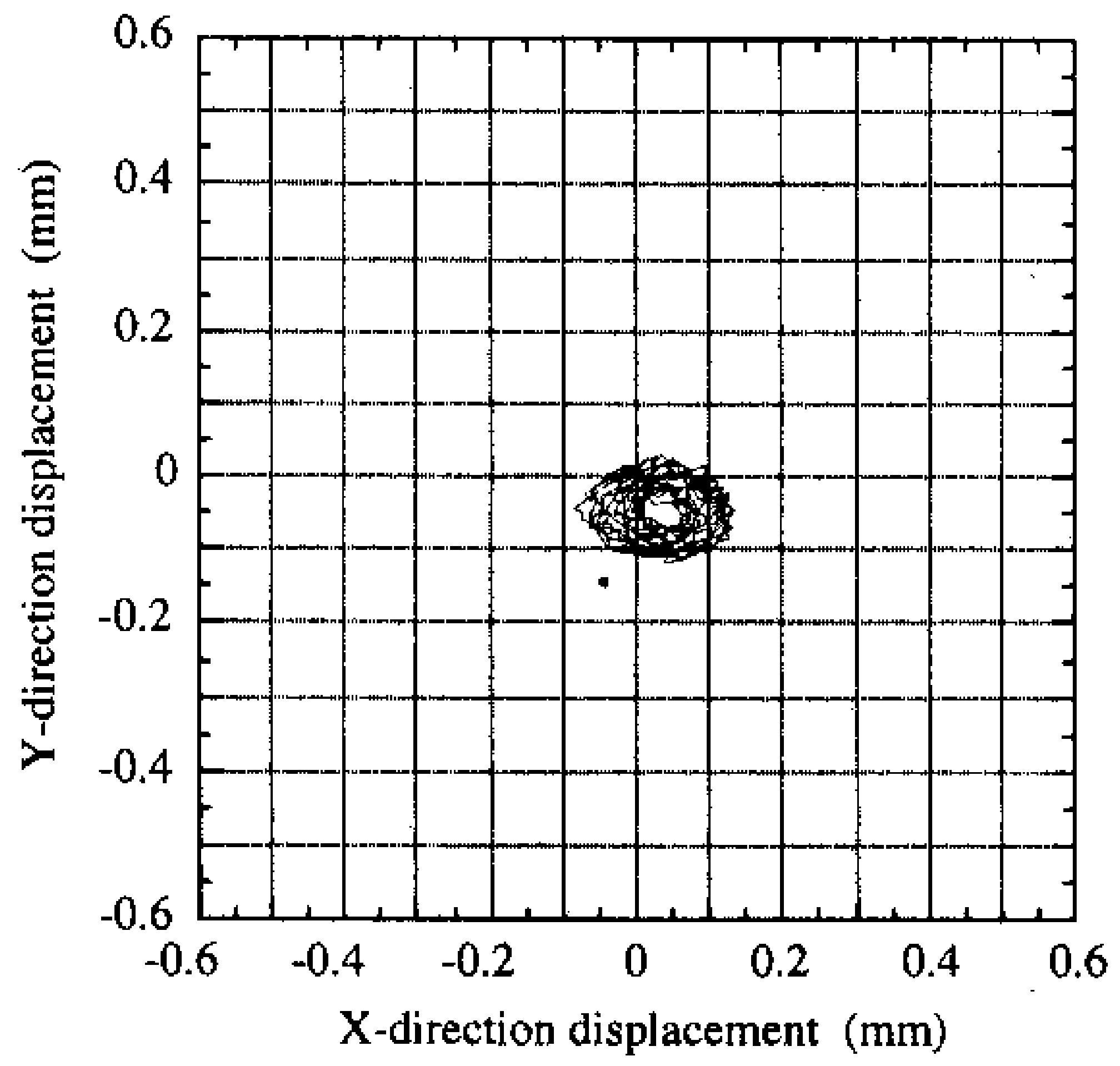

Fig. 4. Vibration characteristics with the nonuniformity in rotor.

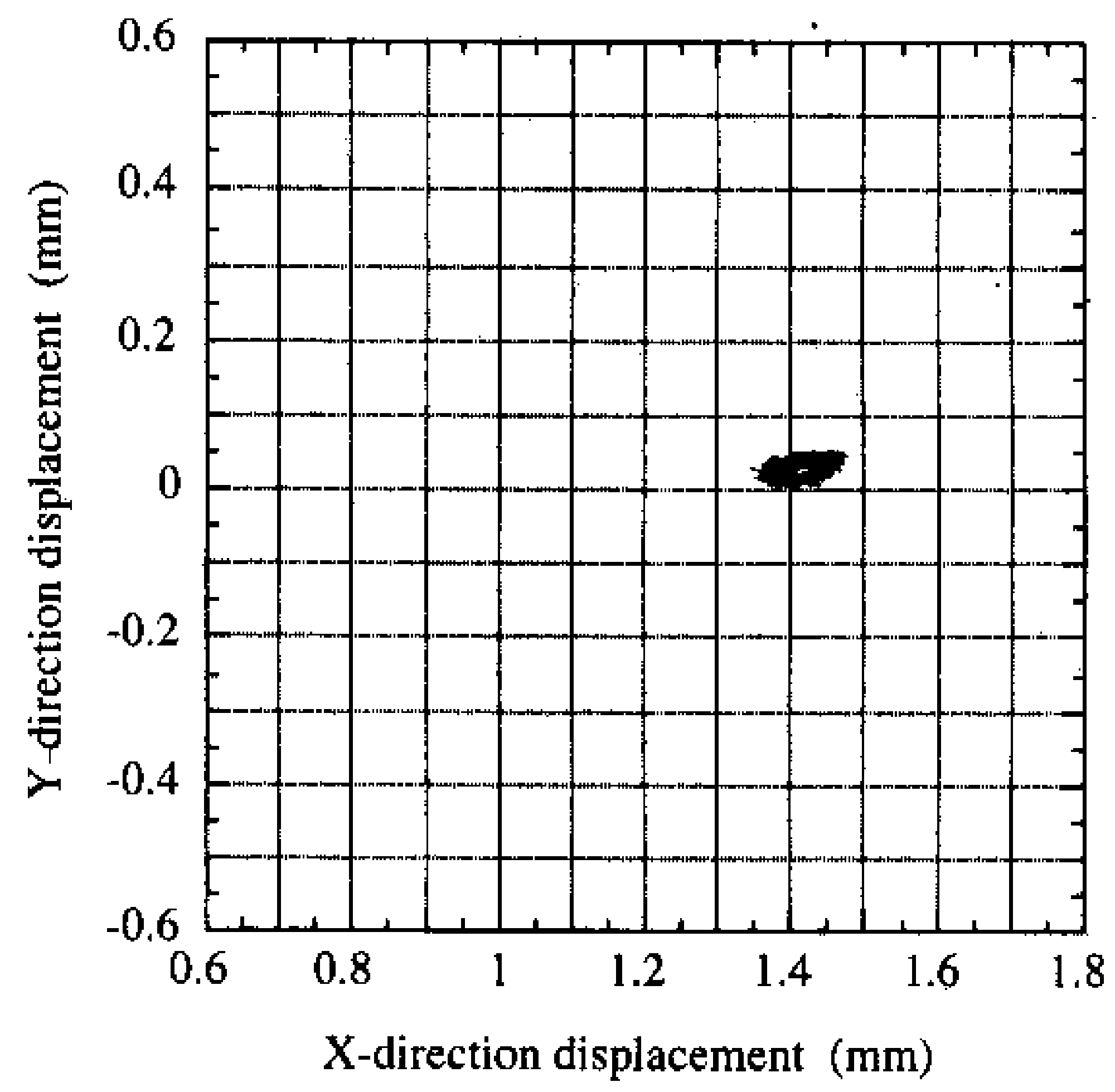

Fig. 5. Vibration characteristics with the nonuniformity in stator.

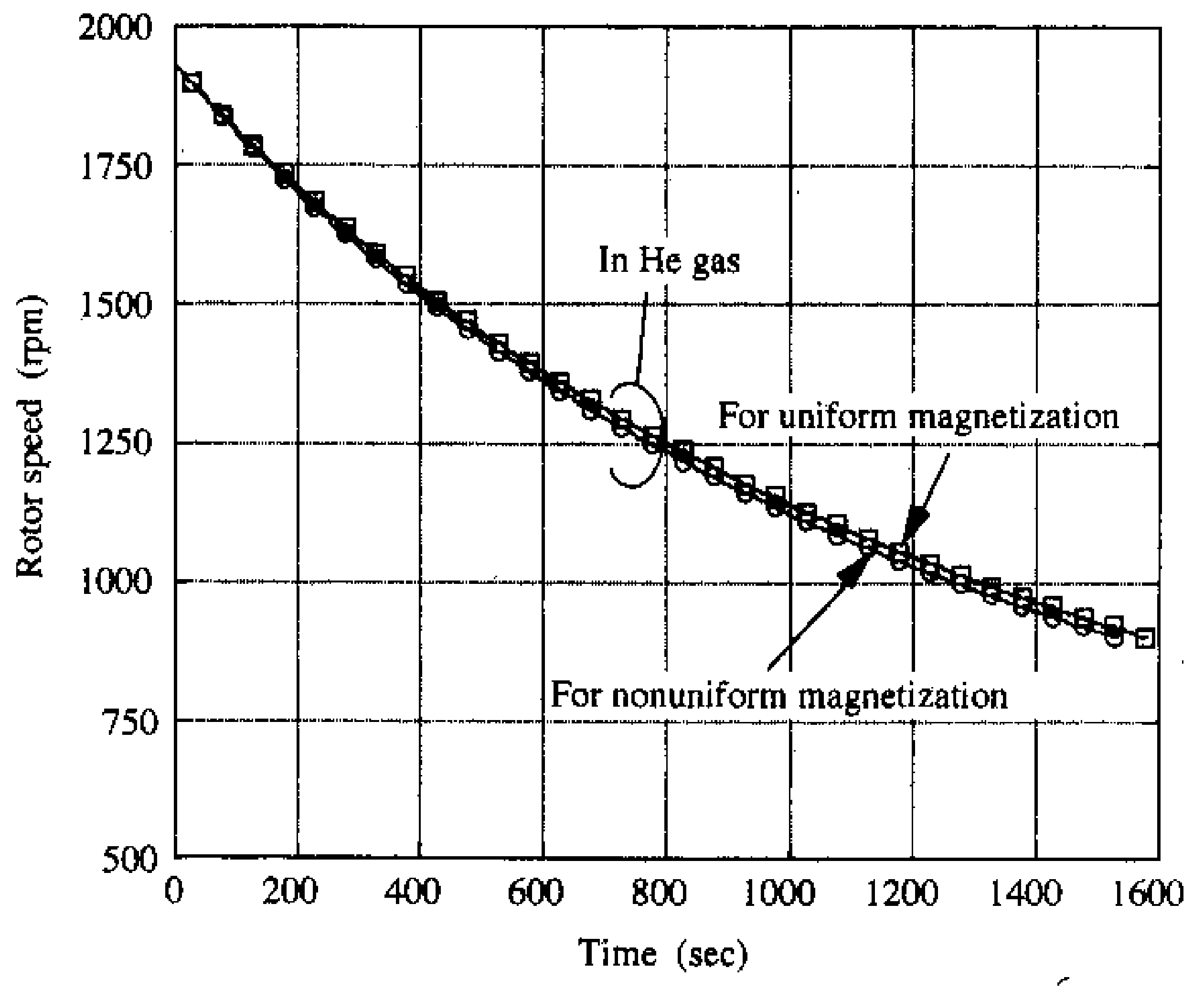

Fig. 6. Deceleration characteristics of the rotor.

difference of stored energy was about 2.2 joule after $1400 \mathrm{sec}-$ onds. This is due to the very low conductivity of strontium fer rite magnet $(<10000 \mathrm{~S} / \mathrm{m})$. The generation of eddy current in 


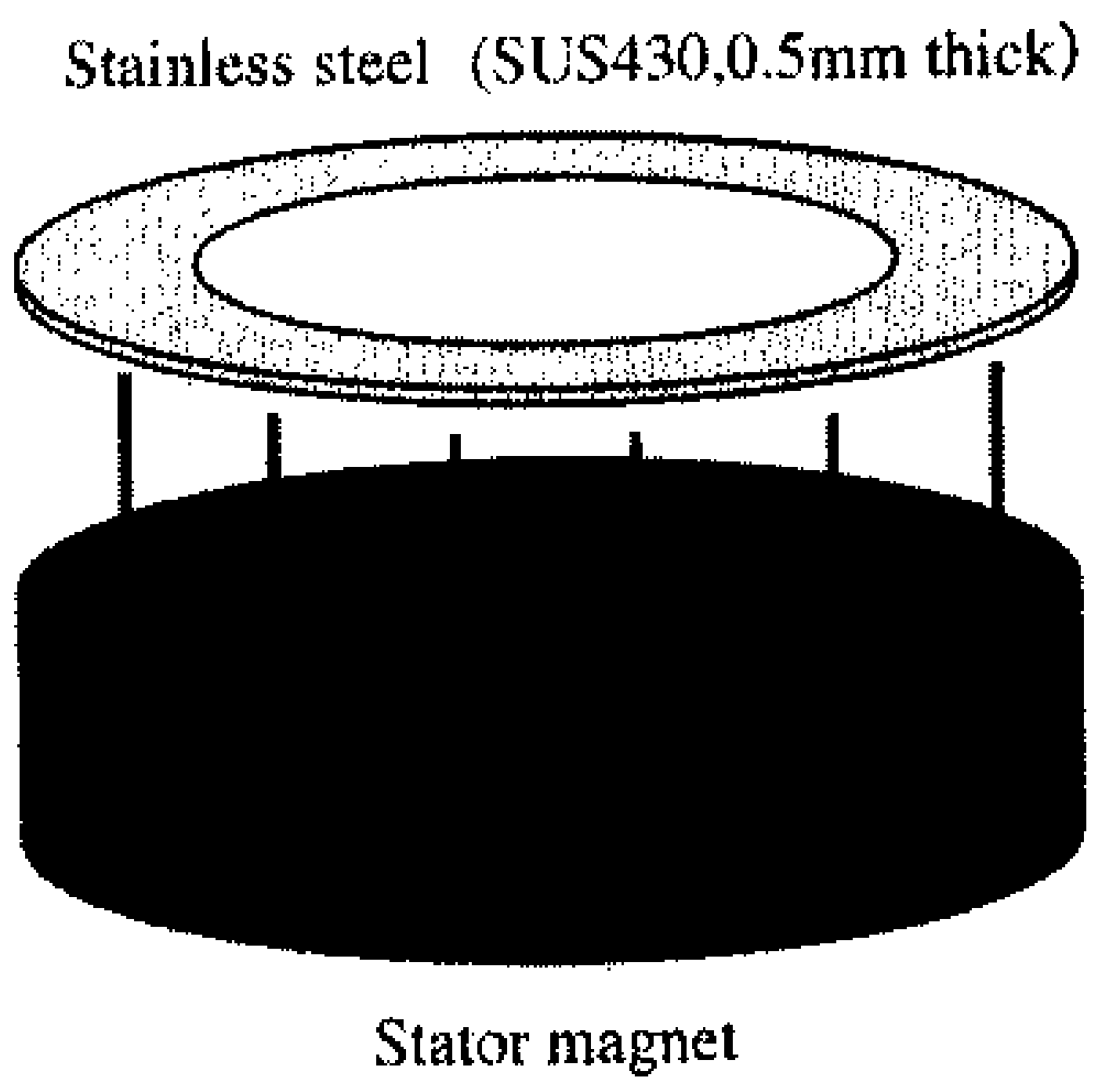

Fig. 7. Configuration of stainless-steel plate.

the rotor magnet due to the nonuniform magnetization is not so severe.

\section{METHOD OF IMPROVEMENT}

Since the replacement of the magnets is a costly solution, the other options are explored. As both the stator and the rotor PM assembly consists of more than one magnet, magnets in the assembly are rotated to change the relative position with respect to each other. Even though this has improved the flux density distribution compared to the earlier situation, it was not possible to operate the system under stable operating condition. From the experimental observation it has been noticed that even unequal but smooth flux density distribution has a strong positive effect on the vibration characteristics. If the flux distribution is made smooth, the level of vibration could be reduced to a low value. In order to make the field distribution smooth for the magnets, different possibilities have been tried and a simple and cheap solution has been found. Different thicknesses of metal plate made up of different materials are attached to the stator magnet as shown in Fig. 7 and experiments were carried out. Satisfactory performance was obtained with a $0.5 \mathrm{~mm}$ thick stainless steel plate. Due to the presence of slight magnetization in the stainless steel plate, it changes the flux distribution of the PM assembly. At the same time as the conductivity of the stainless steel is low, the eddy current loss also will be low. The flux density distribution has been measured and is shown in Fig. 8. It is seen that the flux density distribution has become smooth although there is a slight reduction of absolute magnitude of the flux density.

As the strontium-ferrite magnet is brittle in nature, there is difficulty of fixing the plate on the rotor magnet as the possibility of flying away at high speed exists. With the plate the system has been made operational and the vibration characteristics were measured. Fig. 9 shows the vibration characteristics of the rotor with the stainless steel plate fixed on the stator magnet. It is seen that the level of vibration has been reduced and also the rotor displacement from the central position is negligible.

\section{CONCLUSION}

This paper has studied the effect of nonuniformity of the magnetization of the permanent magnet on the performance of the

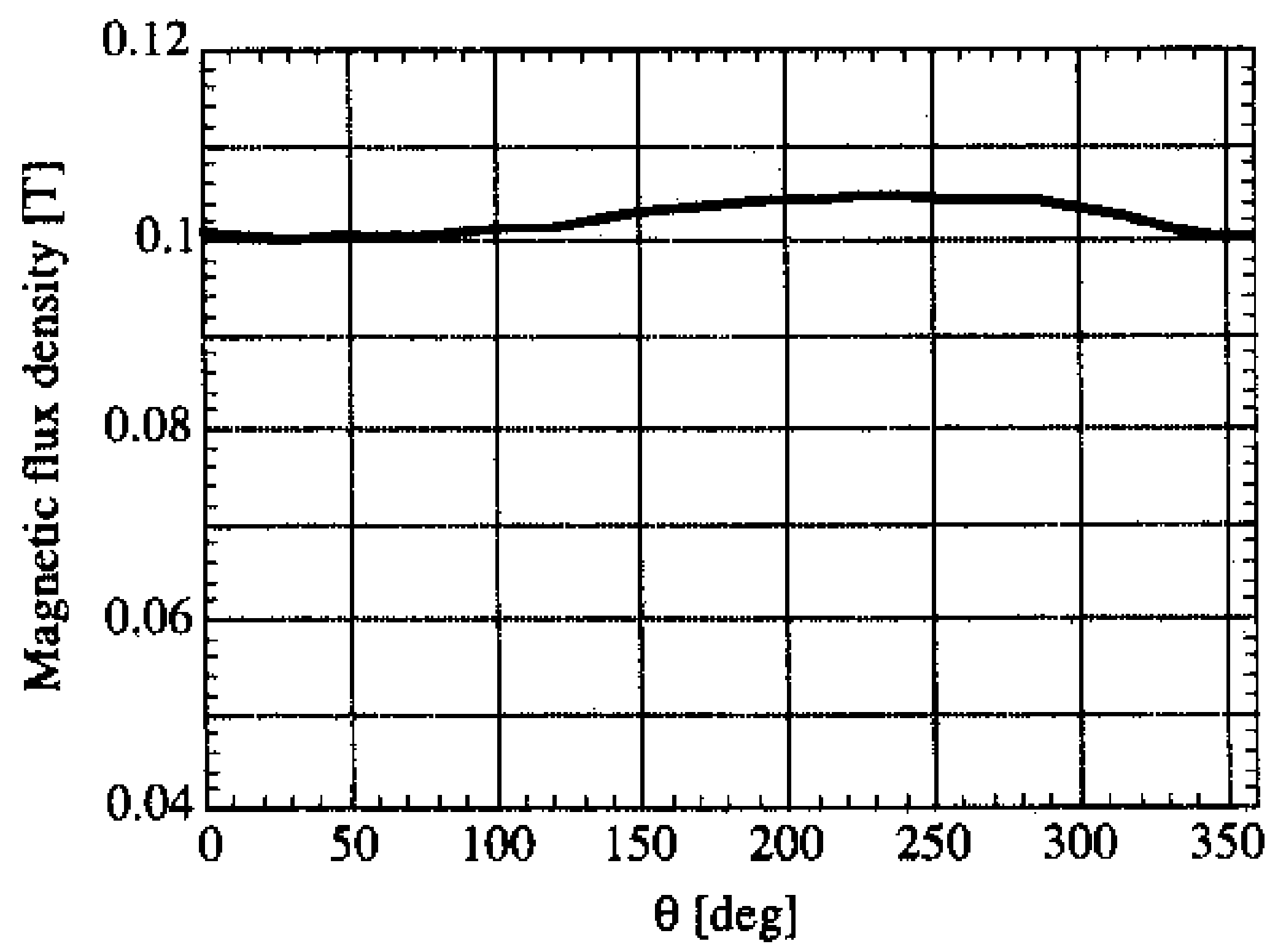

Fig. 8. Flux density distribution.

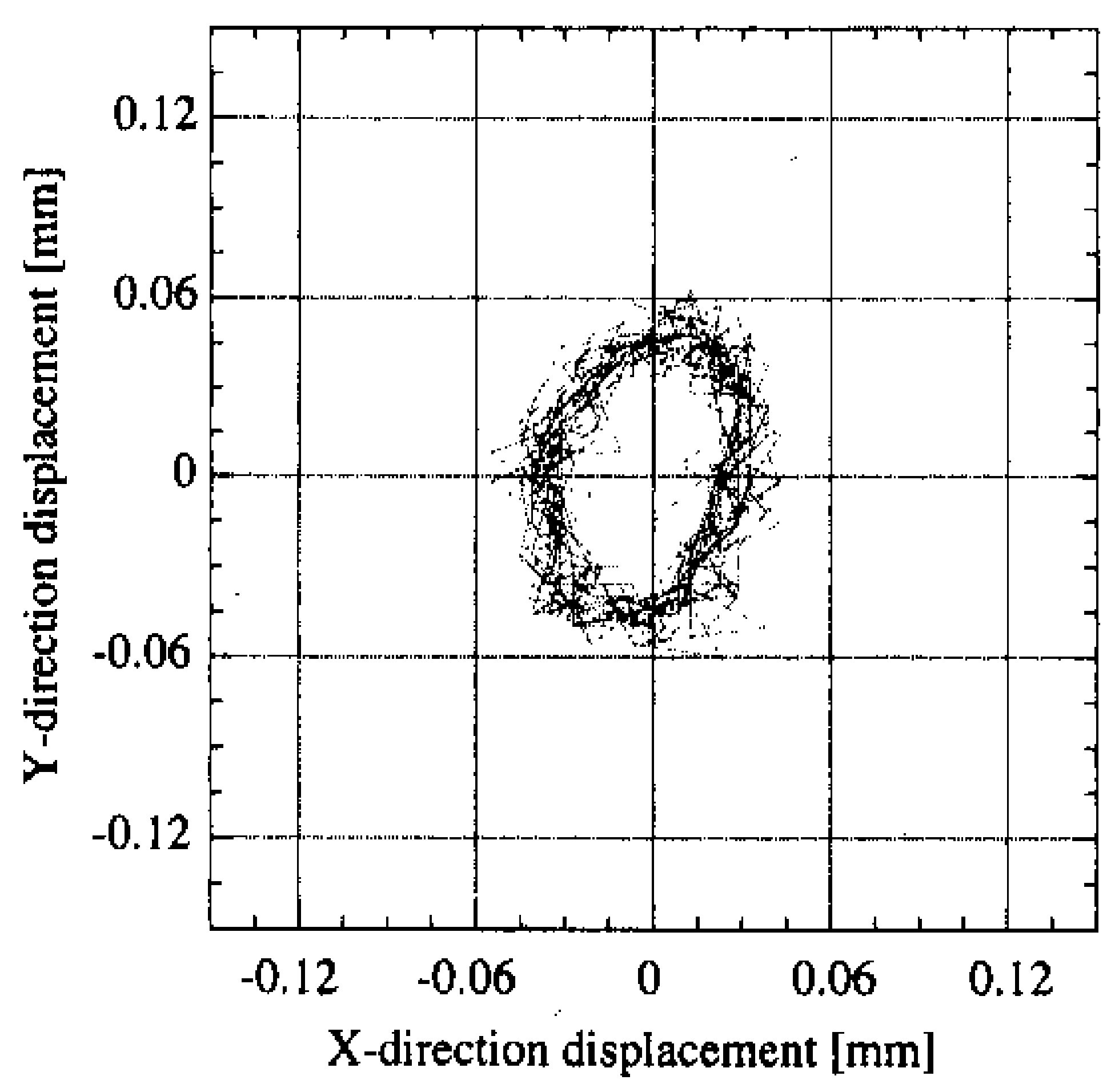

Fig. 9. Vibration characteristics of the rotor.

repulsive type magnetic bearing system. It has been seen that due to the nonuniformity of magnetization, unwanted vibration of the rotor were observed and the rotor was displaced from the central position. A simple method of improvement has been discussed which has smoothed the flux distribution and consequently there is a reduction of vibration level.

\section{REFERENCES}

[1] S. C. Mukhopadhyay, T. Ohji, M. Iwahara, S. Yamada, and F. Matsumura, "Comparative studies of levitation and control performances of two types of single axis controlled repulsive type magnetic bearing," NASA Periodicals, vol. NASA/CP-1998-207654, pp. 393-405, May 1998.

[2] S. C. Mukhopadkyay, T. Ohji, M. Iwahara, and S. Yamada, "Design, analysis and control of a new repulsive type magnetic bearing," IEE Proceedings on Electric Power Applications, vol. 146, no. 1, pp. 33-40, January 1999.

[3] T. Ohji, S. C. Mukhopadhyay, M. Iwahara, and S. Yamada, "Permanent magnet bearing for horizontal and vertical shaft machines-A comparative study,"J. Appl. Phys., vol. 85, no. 8, pp. 4648-4650, Apr. 1999. 